\title{
Feaella (Tetrafeaella) obscura sp. nov. - a new pseudoscorpion species from the Maldives (Arachnida, Pseudoscorpiones), and an updated identification key to the subgenus Feaella (Tetrafeaella)
}

\author{
János Novák ${ }^{1}$, Michelle Lorenz ${ }^{2}$, Danilo Harms ${ }^{2}$ \\ 1 Hungarian Natural History Museum, Department of Zoology, Baross u. 13, H-1088 Budapest, Hungary \\ 2 Zoological Museum, Center of Natural History, Universität Hamburg, Martin-Luther-King-Platz 3, 20146 Hamburg, Germany \\ http://zoobank.org/4D358991-0404-4FF9-A9BD-0E9288B5E355 \\ Corresponding author: János Novák (novakjanos01@gmail.com)
}

Academic editor: Pavel Stoev • Received 27 July 2020 • Accepted 8 September 2020 • Published 19 November 2020

\begin{abstract}
The Feaellidae Ellingsen, 1906 is a small but ancient family of pseudoscorpions with 20 extant species across the Southern Hemisphere, and fossils from the Lower Cretaceous of Myanmar and the Eocoene of Europe. Here, we describe and illustrate Feaella (Tetrafeaella) obscura sp. nov. as a new species from the Maldives archipelago in the Indian Ocean. This is the first record of Feaella from a young oceanic island and may indicate a potential for long-distance dispersal in this lineage. We also elevate Feaella (T.) capensis nana Beier, 1966 to full species rank as $F$. (T.) nana Beier, 1966 and provide an identification key to the members of the subgenus Feaella (Tetrafeaella), thereby facilitating the identification of species.
\end{abstract}

\section{Key Words}

biogeography, dispersal, endemism, false scorpion, taxonomy

\section{Introduction}

Pseudoscorpions belonging to the family Feaellidae Ellingsen, 1906 are amongst the most unusual arachnids and have a spectacular morphology that includes a carapace with multiple frontal lobes, a dorsoventrally flattened and heavily sclerotised body, and pedipalps that are stout, heavily armed and without a venom gland in both fingers (Harvey et al. 2016b; Judson 2017). The family has a Pangaean distribution and amber fossils are known from the Lower Cretaceous of Myanmar (Henderickx and Boone 2016) and Baltic amber in Europe (Hendrickx and Boone 2014; Harms and Dunlop 2017), whereas twenty extant species are found in tropical and subtropical regions in central and southern Africa, north-western Australia, tropical India and Sri Lanka, the Seychelles, Madagascar, and Brazil (Fig. 1) (Harvey 2013, 2018; Harvey et al. 2016a, b; Judson 2017).
Their strange morphology aside, feaellids are also of fundamental importance in understanding the evolution of character systems in pseudoscorpions (Benavides et al. 2019). According to the most recent transcriptomic analysis (Benavides et al. 2019), Feaellidae and its sister-family Pseudogarypidae Chamberlin, 1923 are the sister group to all pseudoscorpions with venom glands in the pedipalp fingers and placed within their own suborder Atoposphyronida Harvey, 2019. The present-day distribution of the family and the fossil record (Harms and Dunlop 2017) suggests that this is a remnant lineage that may have survived in relictual habitats across the Southern Hemisphere.

Feaellidae are grouped into two subfamilies, Feaellinae (Ellingsen, 1906) and Cybellinae Judson, 2017 (Judson, 2017). Feaellinae comprises two genera, Feaella Ellingsen, 1906 from Africa, India, Madagas- 


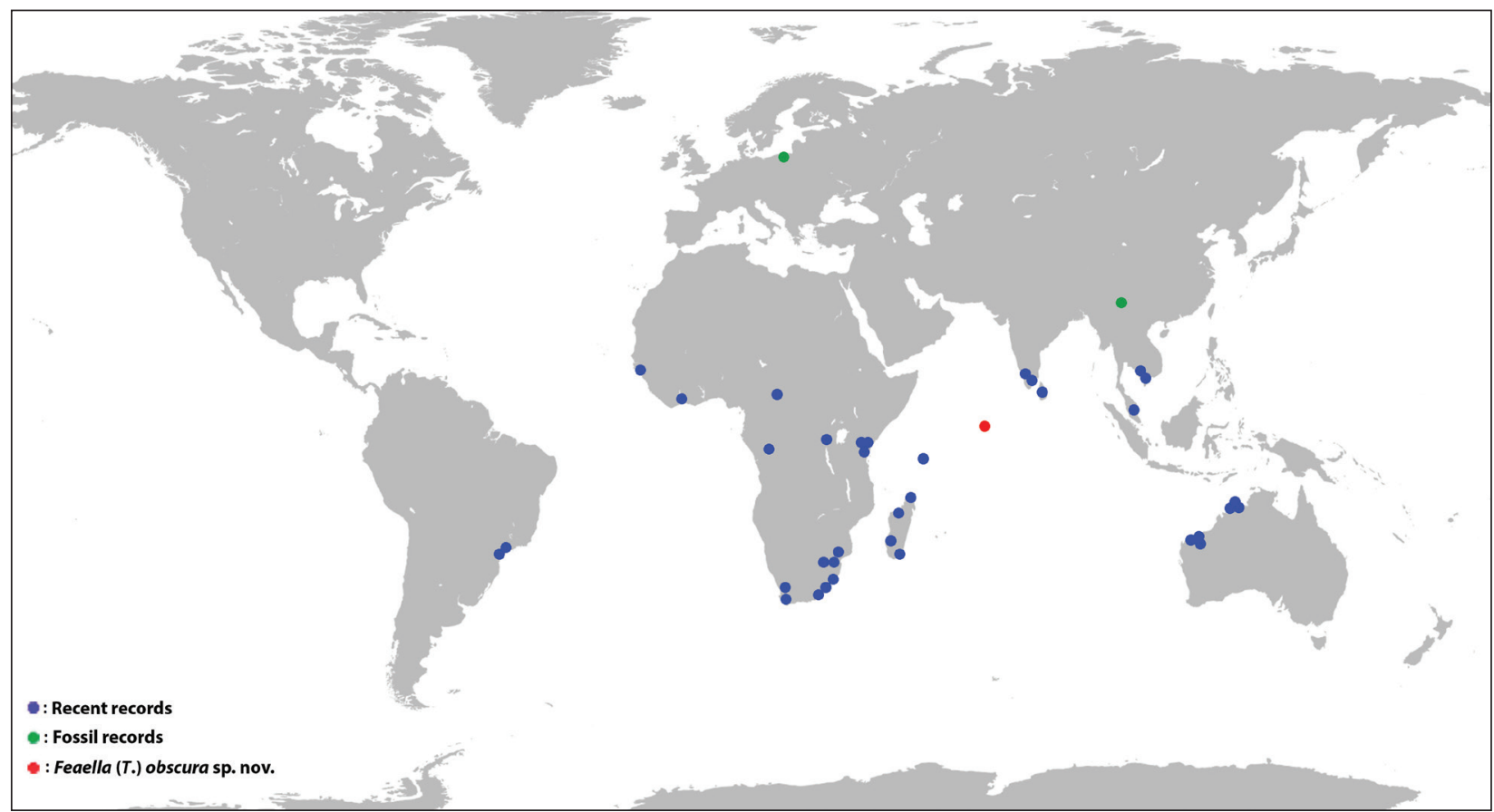

Figure 1. Known distribution of the family Feaellidae. Circle colours: blue = Recent records; green = fossil records; and red $=F$. $(T$. $)$ obscura sp. nov.

car, the Seychelles, Sri Lanka and Australia (Harvey 2013); and Iporangella Harvey, 2016 from South America (Harvey et al. 2016b). Depending on the number of frontal lobes, Feaella is presently divided into three subgenera: Feaella (Feaella; six processes), Feaella (Difeaella; two processes), and Feaella (Tetrafeaella; four processes) (Mahnert 1982). Most species are narrow-range endemics that are only known from a single or few localities, have poor dispersal capacities, and are restricted to specific habitats such as rocky outcrops (Harvey et al. 2016a), near or in caves (Batuwita and Benjamin 2014, Judson 2017; Harvey 2018), or rainforest habitats (Harvey et al. 2016b). In Africa and South America, these animals have been collected from leaf litter (Mahnert 1982; Harvey et al. 2016a, b) but in mainland Australia they have been found under rocks (Harvey et al. 2016a), although Harvey (1989) also recorded Feaella anderseni from vine thicket litter. In eastern Asia the only known records are from within caves (Judson 2017; Harvey 2018).

In this paper, we are describing Feaella (Tetrafeaella) obscura sp. nov. from the Maldives, which are comprised predominantly of young reef-islands and atolls in the Indian Ocean (Kench et al. 2005). The description is based on old museum specimens rather than recently collected material but our species does not match any of the described species and documents the first possible case of oceanic dispersal in this lineage. To diagnose this species accurately and assist the identification of Feaella species across the world, we also provide a key to the species of Feaella (Tetrafeaella). Finally, we also discuss the taxonomic status of Feaella (Tetrafeaella) capensis nana Beier, 1966 from southern Africa and elevate this population to species rank.

\section{Material and methods}

The specimens were found during an inventory in the collections of the Hungarian Natural History Museum (HNHM) and stored in 70\% ethanol. They were cleared in a 3:1 mixture of lactic acid and gelatine to be examined with a Zeiss Stemi 2000-c stereomicroscope and a Zeiss Axioskop 2 light compound microscope. Drawings and measurements were made with the aid of the Zeiss Axioskop 2 microscope. Measurements were taken using the Olympus Soft Imaging analySIS work 5.0 software. Digital images were taken with a custom-made BK Plus Lab System by Dun, Inc. with integrated Canon EOS 7D Mark II, microscopic lens $(5 \times$ and $10 \times$ magnification) and the Zerene stacker version 1.04 software. Scanned electron images were taken from temporarily dried specimens mounted on copper wire, using a Hitachi TM4000 Plus scanning electron micrograph (SEM). Mensuration follows the reference points in Chamberlin (1931) as does the terminology, except for modifications for the pedipalps and chelal trichobothria (Harvey 1992), the chelicera (Judson 2007), and the faces of the appendages (Harvey et al. 2012).

\section{Abbreviations}

Cheliceral trichobothriotaxy: $b s=$ basal seta; $s b s=$ subbasal seta; is = interior seta; es = exerior seta; $l s=$ laminal seta; $g s=$ galeal seta. Chelal trichobothriotaxy: $e b=$ externo-basal; $e s b=$ externo-subbasal; est $=$ externo-subterminal; et $=$ externo-terminal; $i b=$ interno-basal; $i s b=$ interno-subbasal; ist $=$ interno-subterminal; $i t=$ interno-terminal; $t=$ terminal; $s t=$ subterminal; $s b=$ subbasal; $b=$ basal; $d t=$ duplex trichobothrium. 


\section{Results}

\section{Taxonomy}

\section{Superfamily Feaelloidae Ellingsen, 1906 \\ Family Feaellidae Ellingsen, 1906 \\ Subfamily Feaellinae Ellingsen, 1906}

Remarks. The genus Feaella is divided into three subgenera: Feaella (Feaella), Feaella (Difeaella), and Feaella (Tetrafeaella) based on the number of frontal lobes on the carapace (Mahnert 1982). Our new species has four lobes and is assigned to Tetrafeaella, hence the diagnosis is against similar species with four protuberances. The species can also be diagnosed against the east Asian genus Cybella Judson, 2017 which lacks pleural sclerites on the abdomen which are obvious in our species.

\section{Feaella (Tetrafeaella) obscura sp. nov.}

http://zoobank.org/C6FF5DD9-BE35-4AEA-A049-3BB24048D9DB Figs 2A-F, 3A-H, 4A-F, 5A-G

Type material. Holotype female from the Maldives, Kabudu Island (might refer to Kaudu $\left[0^{\circ} 17^{\prime} \mathrm{N}, 73^{\circ} 1^{\prime} \mathrm{E}\right]$ or Kandudu Islands [ $\left.2^{\circ} 19^{\prime} \mathrm{N}, 72^{\circ} 55^{\prime} \mathrm{E}\right]$ ), June 1984, leg: Győző Horváth. [On the label: Maldives, Kabudu sz., 1984.VII. leg.: Győző Horváth] (HNHM Pseud-2009). Paratypes: 1 male (HNHM Pseud-2010) and 1 female (ZMH-A0003101); all same data as holotype.

Etymology. The name of the species refers to the obscure evolutionary and geographic origins of the species that is unlikely to have evolved on the young island that is the locus typicus.

Distribution. Maldive Islands (Fig. 1).

Diagnosis. A typical Feaella (Tetrafeaella) habitus (Figs 2A, B, 3A) that differs from all the other species of the subgenus by the following combination of characters: with the anteromedian lobes of carapace being closer to each other than to the anterolateral ones; anterolateral pair approximately as broad as anteromedian pair, anteromedian lobes longer. Palpal trochanter with prolateral triangular protuberance, femur very robust $(1.70-1.76 \times)$ with two pronounced triangular process on prolateral corner near base. Chelae are approximately as long as the palpal femora. Chelae with dorsal protuberance at basal third of finger, and a large medial tooth at the base of each fingers. Chelal trichobothriotaxy: esb and est situated on basal third of retrolateral face; $i b$, is $b$ and ist situated basally; $e b$ and it situated subdistally; $d t$ situated distally; $e s b$ midway between $e s t$ and $i s b$; ist equidistant from est and $e s b$; isb is closer to $i b$ than to ist; on the movable chelal finger $t$ and $s b$ are situated midway between $b$ and st. Pedal coxa I with medioposterior depression (coxal pit), a single primary coxal spine posteriorly; coxa II with 9 secondary spines in males and 8-11 in females. Pleural membrane with a dorsal row of 15 and a ventral row of 14 sclerotised pleural platelets. See detailed differentiation from the most similar species in the Differential diagno- sis, and differentiation from all the other species of the subgenus in the key.

Description. (Holotype female, paratype male and female). Colour and cuticular surface (in alcohol): sclerotised parts reddish-brown, with reticulated cerotegument (Fig. 2A-F).

Setae: most vestitural setae short, slightly curved, inconspicuous and acuminate.

Chelicera (Fig. 5A): hand with five setae, is and $l s$ adjacent to each other, movable finger with subdistal seta. Galea thick, without rami. Fingers without teeth. Serrula exterior with ca. 16 blades, lamina exterior absent. Rallum absent.

Pedipalps (Figs 2F, 5B): trochanter with prolateral triangular protuberance, femur very robust with two pronounced triangular process on prolateral corner near base, $0.63-0.69 / 0.37-0.40(1.70-1.73 \times)$ in females and $0.51 / 0.29(1.76 \times)$ in male; patella conical, and with two lyrifissures at base, $0.51-0.54 / 0.18-0.19(2.83-2.84 \times)$ in females and $0.41 / 0.14(2.93 \times)$ in male; chela tubular (Figs 3G, 4A-F, 5C), chela (with pedicel) $0.60-0.61$ in females and 0.53 in male, chela (without pedicel) 0.57 in females and 0.50 in male; hand without pedicel and longer than broad. Fixed chelal finger and hand with eight major trichobothria, plus duplex trichobothrium $(d t)$, movable chelal finger with four trichobothria: esb and est situated on basal third of retrolateral face; $i b$, is $b$ and ist situated basally; $e b$ and it situated subdistally; $d t$ situated distally; esb midway between est and isb; ist equidistant from est and $e s b$; isb is closer to ib than to ist. On the movable chelal finger $t$ and $s b$ are situated midway between $b$ and st (Fig. 5C). Venom apparatus absent. Chelal hand very small; retrolateral condyle rounded; with dorsal protuberance at basal third of finger (Fig. 5C). Chelal teeth large, retrorse and diastemodentate: fixed finger with two parallel marginal dental line, one with 11 and one with 9 teeth, 9 prolateral and 7 distal teeth in male; $12-13$ and 9-13 marginal, 9-10 prolateral and 3-4 distal teeth in females; movable finger with two parallel marginal dental line with $9+9,9$ prolateral and 7 distal teeth in male; 12 and 9 marginal, 9-10 prolateral and 6 distal teeth in females; plus a large medial tooth at the base of each finger. Movable chelal finger with several specialised, lanceolate setae midway between $t$ and tip of finger; located in a depression (Fig. 3H).

Carapace: anterior margin with four lobes, the anteromedian lobes are closer to each other than to the anterolateral ones; anterolateral pair approximately as broad as anteromedian pair, anteromedian lobes longer (Figs 2D, 3E). Four lobes between eyes. Lateral margins of carapace nearly parallel, slightly widened medially; carapace in females $1.27-1.28 \times$, in male $1.24 \times$ longer than broad; with two pairs of eyes situated on tubercles away from anterior carapace margin; all eyes with tapetum; with numerous inconspicuous setae; with a pair of postero-lateral processes; shallow anterior and posterior furrows present. Three slit-like lyrifissures at the level of posterior one-fourth of carapace on each side, and two near posterior base. 

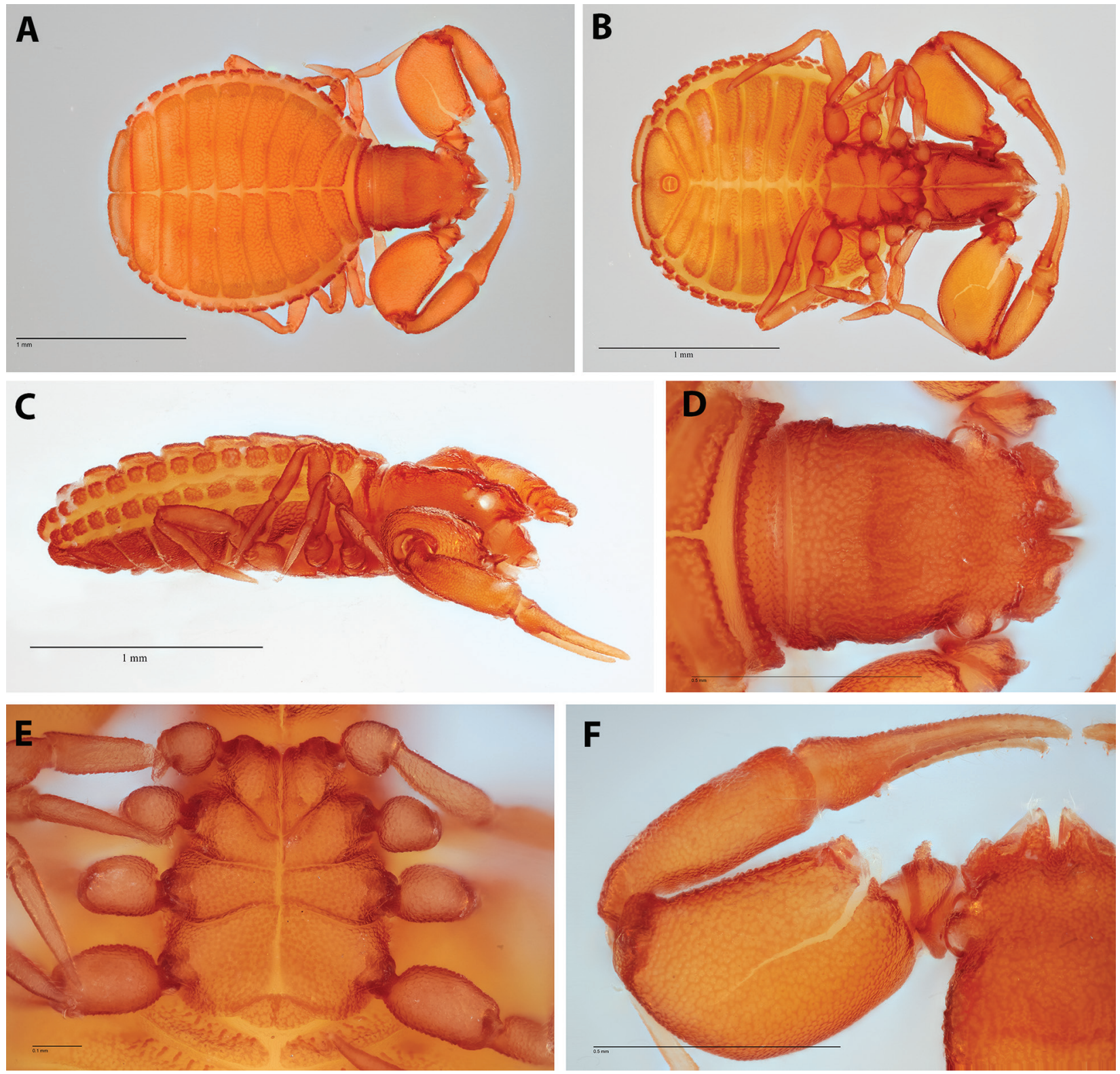

Figure 2. Feaella (Tetrafeaella) obscura sp. nov, female holotype (HNHM Pseud-2009). A. Body, dorsal view; B. Body, ventral view; C. Body, lateral view; D. Carapace, dorsal view; E. Coxal region; F. Left pedipalp, dorsal view.

Coxal region (Figs 2E, 3B): pedipalpal coxa with strong basal lateral processes; with numerous small setae and 3 acuminate apical setae. Coxa I with medioposterior depression (coxal pit), a single primary coxal spine posteriorly; coxa II with 9 secondary spines in male and $8-11$ in females (Fig. 3C). Pedipalpal coxa somewhat longer as combined length of leg coxae I-IV.

Legs (Fig. 5D, E): claws simple, arolium shorter than claws. Metatarsi and tarsi fused. Each patella with a shallow dorsal depression. Tarsi without tactile setae, vestitural setae short and acuminate. Patellae I and II slightly shorter than femora I and II; patellae III and IV nearly twice as long as femora III and IV.

Abdomen: longer than broad, somewhat ovoid; tergites II-IX and sternites IV-X with distinct median suture lines; tergite XI and sternite XI fused; tergite XII and sternite XII (anal sclerites) strongly scle- rotised; most segments with numerous setae; tergite XII and sternite XII with two setae; anal region with raised circular rim (Fig. 3D). Setae of sternites II and III longer than vestitural setae. Pleural membrane with a dorsal row of 15 and a ventral row of 14 sclerotised pleural platelets.

Genital region: Female (Figs 3F, 5F): 10 acuminate microsetae on each plate. Male (Fig. 5G): 40-45 acuminate microsetae on genital plate. Inner genital structures could not be clearly seen.

Measurements (in $\mathrm{mm}$, ratios in parentheses): Male paratype. Body 1.83. Carapace 0.51/0.41 (1.24×). Chelicera 0.19/0.10 $(1.9 \times)$, movable finger 0.085. Palpal femur $0.51 / 0.29(1.76 \times)$, patella $0.41 / 0.14(2.93 \times)$, chela (with pedicel) $0.53 / 0.13(4.08 \times)$, chela (without pedicel) 0.50 , hand (with pedicel) 0.15 , hand (without pedicel) 0.12 , movable finger 0.37 . Leg I. trochanter $0.12 / 0.19$ 

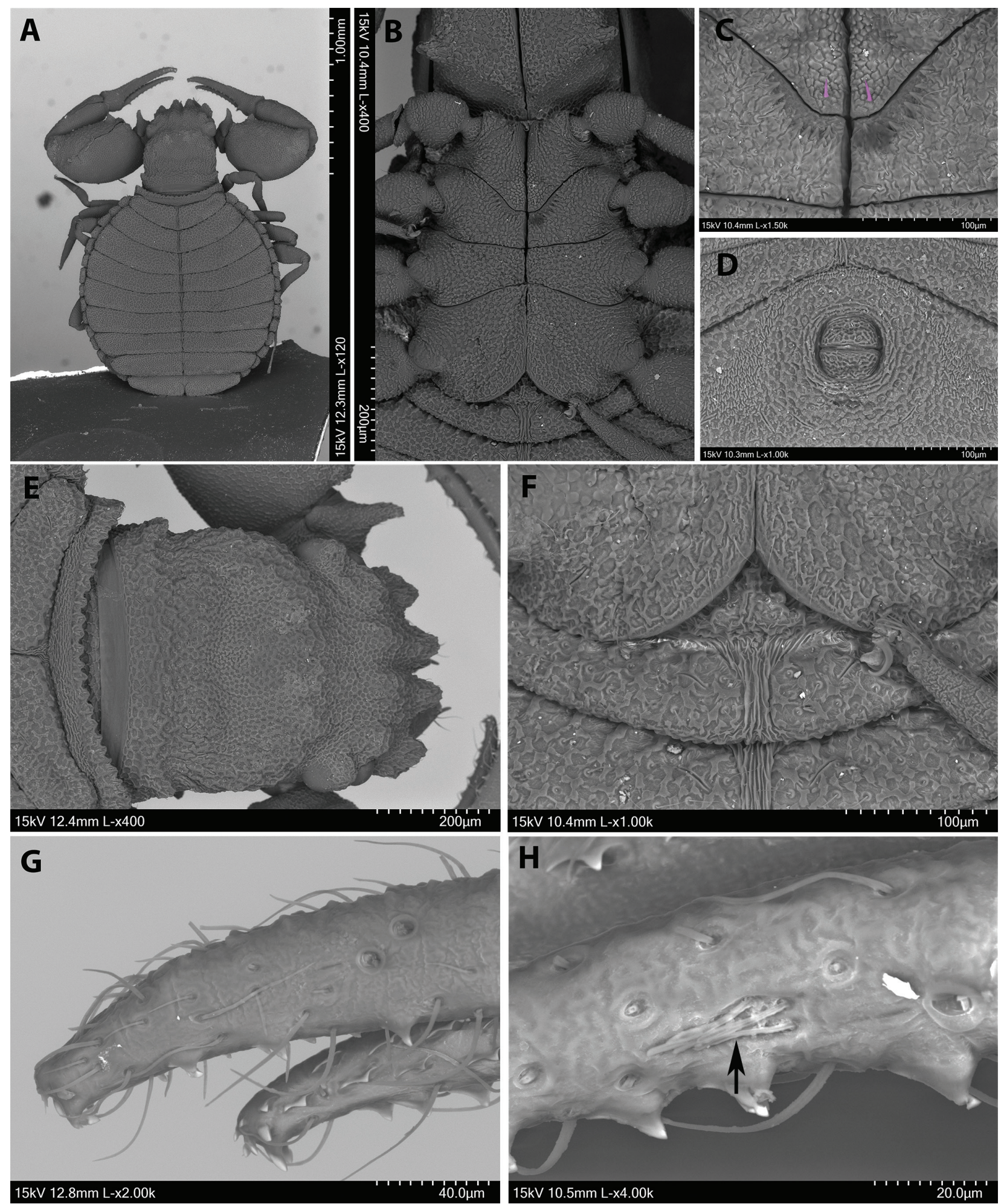

Figure 3. Feaella (Tetrafeaella) obscura sp. nov, female holotype (HNHM Pseud-2009): SEM images. A. Body, dorsal view; B. Coxal region; C. Coxae I and II with medioposterior depression and coxal spines (primary coxal spines of coxae I highlighted in purple); D. Anal region; E. Carapace, dorsal view; F. Female genital region with pedal coxae IV; G. Right chelal tip, dorsal view; H. Specialised, lanceolate setae (marked with arrow) midway between $t$ and finger tip.

$(0.62 \times)$, femur $0.21 / 0.06(3.50 \times)$, patella $0.18 / 0.07$ $(2.57 \times)$, tibia $0.17 / 0.06(2.83 \times)$, tarsus $0.23 / 0.05(4.60 \times)$. Leg IV. trochanter $0.22 / 0.12(1.83 \times)$, femur $0.16 / 0.08$ $(2.00 \times)$, patella $0.28 / 0.10(2.80 \times)$, tibia $0.32 / 0.06(5.33 \times)$, tarsus $0.32 / 0.05(6.4 \times)$.
Females (holotype, followed by paratype in parentheses and then the ratios also in parentheses). Body 2.16 (2.46). Carapace $0.61 / 0.48(0.64 / 0.50)(1.27-1.28 \times)$. Chelicera $0.20 / 0.12(0.21 / 0.12)(1.67-1.75 \times)$, movable finger 0.095 (0.10). Palpal femur 0.63/0.37 (0.69/0.40) (1.70-1.73×), 


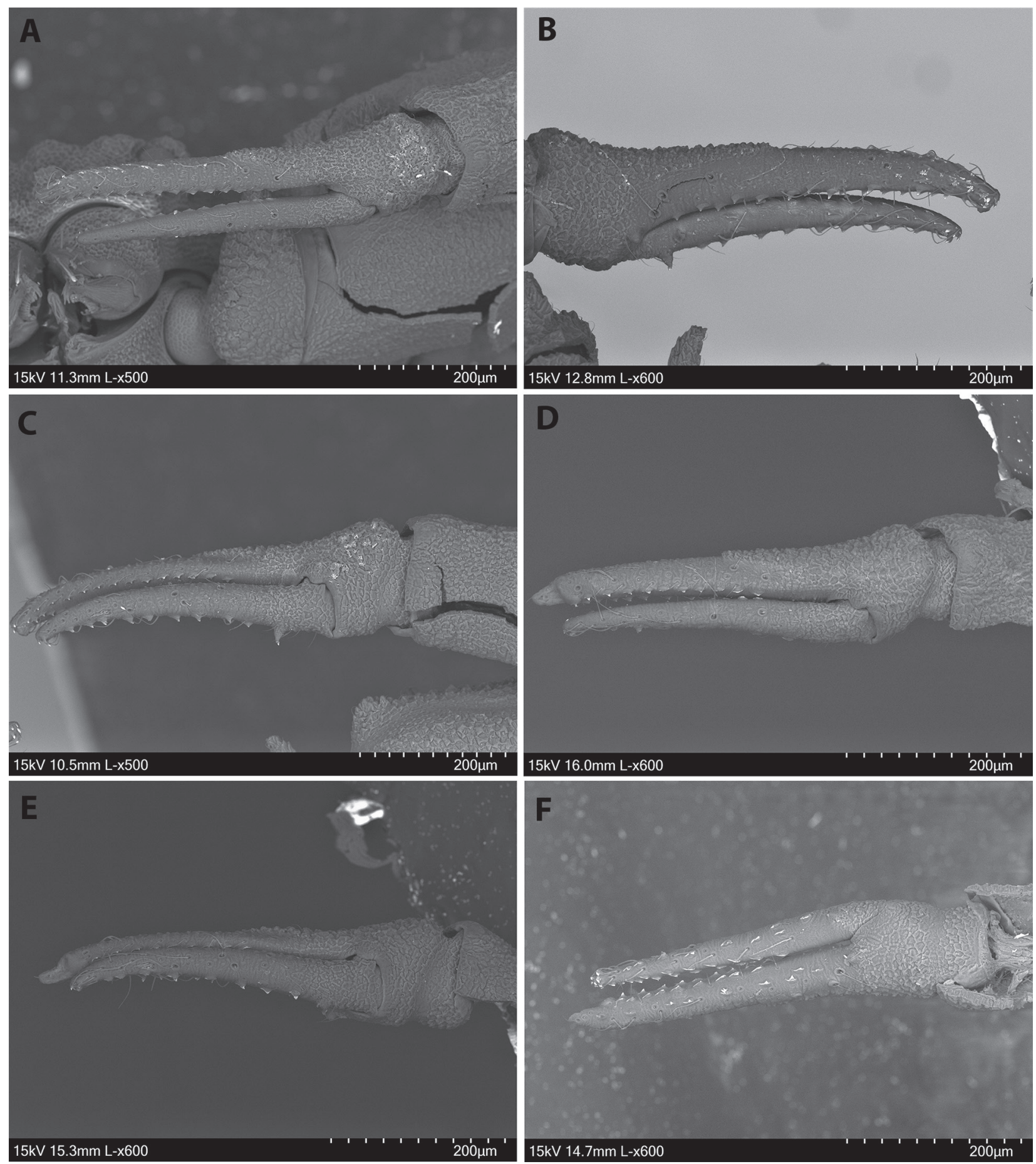

Figure 4. Feaella (Tetrafeaella) obscura sp. nov, female holotype (HNHM Pseud-2009): SEM images. A. Left chela, retrolateral view; B. Left chela, dorsomedial view; C. Left chela, ventral view. Male paratype (HNHM Pseud-2010): SEM images. D. Left chela, retrolateral view; E. Left chela, ventral view; F. Left chela, medial view.

patella $0.51 / 0.18(0.54 / 0.19)(2.83-2.84 \times)$, chela (with pedicel) $0.60 / 0.16(0.61 / 0.16)(3.75-3.81 \times)$, chela (without pedicel) 0.57 (0.57), hand (with pedicel) $0.16(0.17)$, hand (without pedicel) $0.12(0.10)$, movable finger $0.40(0.41)$. Leg I. trochanter $0.15 / 0.11(0.16 / 0.12)(1.33-1.36 \times)$, femur $0.24 / 0.07(0.27 / 0.08)(3.38-3.43 \times)$, patella $0.22 / 0.08$ $(0.21 / 0.09)(2.33-2.75 \times)$, tibia $0.20 / 0.07 \quad(0.22 / 0.07)$ $(2.85-3.14 \times)$, tarsus $0.22 / 0.05(0.22 / 0.05)(4.4 \times)$. Leg IV. trochanter $0.26 / 0.14(0.27 / 14)(1.86-1.93 \times)$, fe- mur $0.18 / 0.10(0.19 / 10)(1.8-1.9 \times)$, patella $0.36 / 0.11$ $(0.37 / 0.12) \quad(3.08-3.27 \times)$, tibia $0.42 / 0.06 \quad(0.44 / 0.07)$ $(6.29-7.00 \times)$, tarsus $0.36 / 0.05(0.38 / 0.06)(6.33-7.20 \times)$.

Differential diagnosis. Aside from Feaella (T.) obscu$r a$ there are twelve species of Feaella (Tetrafeaella): $F$. (T.) affinis Hirst, 1911 (Seychelles); F. (T.) capensis Beier, 1955, F. (T.) mucronata Tullgren, 1907 and $F$. (T.) parva Beier, 1947 (all South Africa), F. (T.) indica Chamberlin, 1931 (India and Sri Lanka), F. (T.) leleupi Beier, 1959 


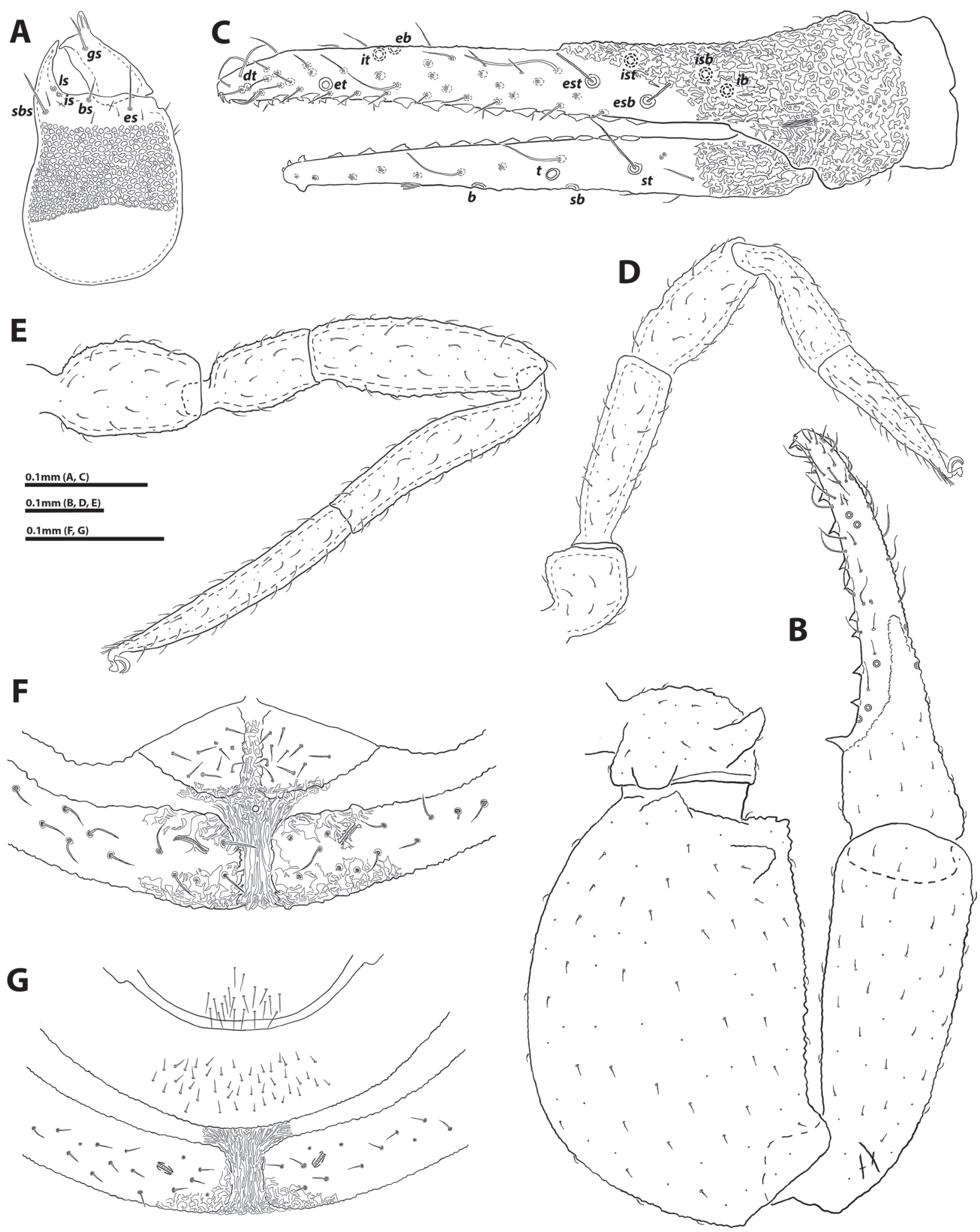

Figure 5. Feaella (Tetrafeaella) obscura sp. nov. A. Right chelicera, dorsal view - female holotype (HNHM Pseud-2009); B. Right pedipalp, dorsal view - female holotype; C. Left chela, retrolateral view - female holotype; D. Leg I, lateral view - female paratype (ZMH-A0003101); E. Leg IV, lateral view - female paratype; F. Female genital region - female holotype; G. Male genital region - male paratype (HNHM Pseud-2010).

(Congo), F. (T.) nana Beier, 1966 comb. nov. (previously treated as a subspecies of capensis but see below), F. (T.) perreti Mahnert, 1982 (Kenya) and the western Australi- an species F. (T.) anderseni Harvey, 1989, F. (T.) callani Harvey et al., 2016, F. (T.) linetteae Harvey et al., 2016 and F. (T.) tealei Harvey et al., 2016. 
Feaella (T.) obscura is most similar in general habitus of carapace and pedipalps and in most characters (see in the key below) to the following species from Africa, India and the Seychelles.

It differs from $F$. (T.) capensis in having a pronounced and triangular dorsomedial process on the prolateral corner of palpal femur near its base (absent in $F$. (T.) capensis), conical shape of the frontal carapace lobes (long and triangular), pleural membrane with a dorsal row of 15 and ventral row of 14 platelets (15 and 15 in $F$. (T.) capensis) (Beier 1955).

Feaella (T.) obscura differs from $F$. (T.) nana in having a pronounced and triangular dorsomedial process on the prolateral corner of the palpal femur near its base (absent in $F$. (T.) nana). Furthermore, in having pleural membrane with a dorsal row of 15 and a ventral row of 14 sclerotised pleural platelets (in $F$. (T.) nana the number of these are 14 and 14). In Feaella (T.) obscura on fixed chelal finger isb much closer to $i b$ than to ist and these three trichobothria do not form a straight row, and trichobothrium $e b$ situated clearly closer to the fingertip than to ist (in $F$. (T.) nana isb, ib and $i s t$ are equally placed and form a straight row, and $e b$ is situated midway between ist and the finger tip) (Beier 1966).

The new species differs from $F$. (T.) indica in having a pronounced and triangular dorsomedial process on the prolateral corner of palpal femur near its base (in $F$. (T.) indica this process is absent). The chelae of $F$. (T.) obscura are approximately as long as the palpal femora (in $F$. (T.) indica these are distinctly shorter than the palpal femora). Furthermore, the palpal femur length/width ratio of $F$. (T.) obscura is $1.70-1.76 \times$ (this value is $1.90 \times$ in $F$. (T.) indica) (Chamberlin 1931; Beier 1932).

In the case of $F$. (T.) affinis Hirst, 1911 trichobotria $s b$ and $s t$ of movable chelal finger are closer to $b$ than $t$ (in the new species $s b$ and $s t$ are situated midway between $b$ and $t$ ). Furthermore, in $F$. (T.) affinis trichobothrium ist of fixed chelal finger is at the level of esb and est is placed distal to them (in $F$. (T.) obscura, ist is equidistant from est and esb) (Mahnert 1978).

\section{Remarks on locality}

The specimens were found in soil samples of the Hungarian Natural History Museum and collected by Mr. Győző Horváth who was a friend of Dr. Sándor Mahunka (former director of HNHM, Department of Zoology) and occasionally collected soil samples for the museum. The collecting label clearly points to the Maldives, however, the island name Kabudu is suspected to be a misspelled form of Kaudu $\left[0^{\circ} 17^{\prime} \mathrm{N}, 73^{\circ} 1^{\prime} \mathrm{E}\right]$ or Kandudu islands $\left[2^{\circ} 19^{\prime} \mathrm{N}, 72^{\circ} 55^{\prime} \mathrm{E}\right]$. Mr. Horváth passed away some years ago and no further data are available.

\section{Biogeography}

The present-day distribution of Feaellidae has been interpreted as a prime example of continental vicariance (Harvey 1989) although this hypothesis is based on dis- tributional data only and requires further testing. One observation that may lend support to this hypothesis is that all species records come from old and stable landmasses (continents or ancient islands such as Madagascar and the Seychelles), with the exception of the Bonaparte Archipelago in north-western Australia which, however, is geologically part of the mainland (Henderson and Johnson 2016). This is a distributional pattern to be expected for poor dispersers with a long evolutionary history.

The present finding is the first record of the Feaellidae from an oceanic island other than the Seychelles which, in contrast to the Maldives, are geologically old and known to support ancient Gondwanan fauna (Gerlach and Marusik 2010). The atolls of the Maldives emerged as recently as 5500-4500 years ago as lagoonal sediments were exposed by shoreline changes (Kench et al. 2005), although volcanic activity in the Maldive Ridge has also shaped this region for as long as 60 million years and many of the atolls have underlying volcanic basalt (Droxler 1992). We cannot exclude the hypotheses that the presence of Tetrafeaella here is a result of vicariance and long-term persistence in an island landscape that changed dynamically over time but dispersal is equally likely, in particular since many islands drowned and re-emerged as sea levels changed. We are not sure where $F$. (T.) obscura originates but we have checked the new species carefully against congeners from India and Sri Lanka, which are the most promising candidates for a source population. Our new species is clearly different from $F$. indica but also from several undescribed species from Madagascar. So, if $F$. (T.) obscura originated elsewhere it must be from a region where the genus is presently undescribed. Dispersal modes are also not clear and passive oceanic drift is as likely as anthropogenic dispersal. The Maldives is a popular tourist destination and timber as well as soil samples are imported regularly from other regions to support the local industry. The evolutionary origins of $F$. (T.) obscura remain enigmatic until fresh samples are being collected for genetic studies.

\section{The status of Feaella (T.) capensis nana Beier, 1966}

While our focus is the description of a new species, the study of relevant literature also reveals inconsistencies in the description of $F$. (T.) capensis from South Africa. The species was originally described from Cape Point in the Western Cape but Beier (1966) also recorded this species from Kruger National Park in Limpopo Province, almost $1700 \mathrm{~km}$ apart. There are several differences in morphology between both populations, including body size (females from Cape Point: $2.6 \mathrm{~mm}$ in body length; $1.7 \mathrm{~mm}$ from Kruger) and chelal length (females from Cape Point: $0.68 \mathrm{~mm} ; 0.40-0.50 \mathrm{~mm}$ from Kruger) but Beier preferred to treat the Kruger populations as a subspecies, $F$. (T.) capensis nana, next to the nominate form Feaella (T.) capensis capensis. Our perception of range sizes in Feael$l a$ has changed drastically since then and recently molec- 
ular studies have shown that most species have extremely small ranges and low dispersal capacities (Harvey et al. 2016a). We also emphasise the morphological differences such as chelal trichobothriotaxy: on the fixed chelal finger of $F$. (T.) capensis capensis isb is much closer to $i b$ than to ist and these three trichobothria do not form a straight row, and trichobothrium $e b$ is situated clearly closer to the fingertip than to ist, whereas in $F$. (T.) capensis nana isb, $i b$ and $i s t$ are equally placed and form a straight row, and $e b$ is situated midway between ist and the fingertip. Fur- thermore, the number of dorsal and ventral rows of sclerotised pleural plates of the pleural membrane are $15+15$ in F. (T.) capensis capensis, and $14+14$ in $F$. (T.) capensis nana (Beier 1955, 1966). Hence, we elevate $F$. (T.) capensis nana to full species rank, forming the new combination $F$. (T.) nana Beier, 1966 comb. nov. We also emphasise that $F$. capensis was recorded from several locations in Zimbabwe (Beier 1964) and, again, these populations are much smaller than the nominate form and likely represent distinct species pending detailed study.

\section{Identification key to the species of the subgenus Feaella (Tetrafeaella)}

Since Chamberlin's first key to the family (Chamberlin 1931) which included four species only, several keys were published for the African fauna (Beier 1955, Mahnert 1982). To better diagnose $F$. (T.) obscura from species with a similar morphology, we provide the following iden- tification key which is constructed based on our new data and the literature (Tullgren 1907; Hirst 1911; Chamberlin 1931; Beier 1932, 1947, 1955, 1959, 1966; Mahnert 1978, 1982; Harvey 1989; Harvey et al. 2016a). The proportions are given for both sexes whenever possible.

1 All four anterior lobes of carapace with approximately equal width, and placed equidistantly from each other. Presence of a pair of enlarged, thick-walled bursa in male genitalia (Australia)...................... 2 [F. (T.) anderseni species-group]

- Clear differences in length and/or in width of anteromedian and anterolateral lobes of the carapace, and/or in the dis.

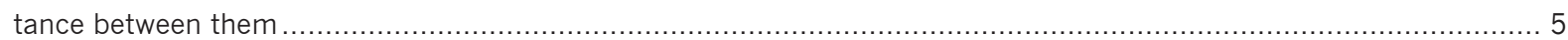

2 Cheliceral rallum present. Pedipalpal femur 1.78-1.91× longer than broad (female); chela with pedicel 0.510-0.580 mm (female) and palpal femur $0.600-0.640 \mathrm{~mm}$ (female) ......................................................... (T.) anderseni

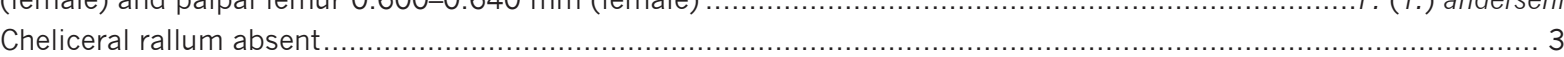

3 Trichobothrium $t$ situated distal to $s b$ on movable chelal finger. Pedipalpal femur $1.73 \times$ (male) and $1.75-1.79 \times(\mathrm{fe}$ male) longer than broad; chela with pedicel 0.555 (male) and $0.645 \mathrm{~mm}$ (female) and palpal femur 0.665 (male) and $0.710 \mathrm{~mm}$ (female)

- $\quad$ Trichobothria $s b$ and $t$ on movable chelal finger approximately at the same level (same distance from the finger basis) .... 4

4 Trichobothrium $s b$ is situated basally to $t$ on movable chelal finger, on fixed finger isb much closer to ib than to ist. Pedipalpal femur $1.77 \times$ longer than broad (male). Smaller species, chela with pedicel $0.560 \mathrm{~mm}$ (male) and palpal femur $0.575 \mathrm{~mm}$ (male)

F. (T.) callani

- Trichobothrium sb is situated opposite to $t$ on movable chelal finger, on fixed finger isb equally distant from ib and ist. Pedipalpal femur 2.06× (male) longer than broad. Larger species, chela with pedicel $0.635 \mathrm{~mm}$ (male) and palpal femur

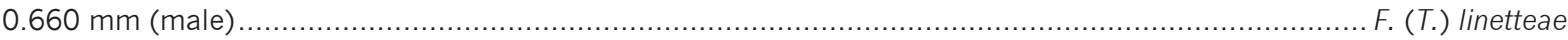

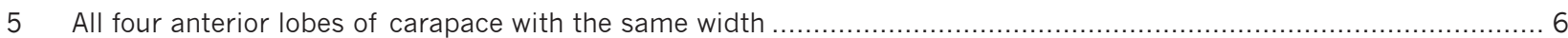

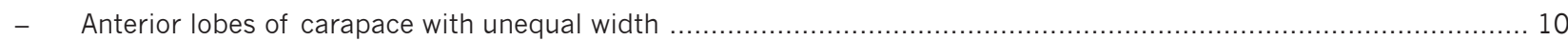

6 Anterior lobes of carapace have approximately equal length. Anteromedian lobes much closer to anterolateral ones than to each other. Pedipalpal femur $1.78 \times$ longer than broad (South Africa, Swaziland)............................ F. (T.) mucronata

- $\quad$ Anteromedian lobes clearly longer than the anterolateral ones ............................................................ 7

7 On fixed chelal finger is $b$, ib and ist are equally placed and form a straight row. Trichobothrium eb is situated midway

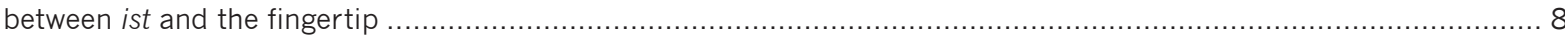

- On fixed chelal finger isb much closer to ib than to ist and these three trichobothria do not form a straight row. Tricho-

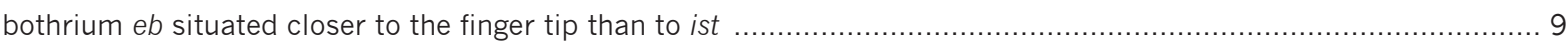

8 All four anterior lobes of the carapace rather conical, the anteromedian lobes somewhat longer than the anterolaterals. Pedipalpal femur robust, $1.77 \times$ (female). Pleural membrane with a dorsal and a ventral row of 14-14 sclerotised pleural platelets. (South Africa).......

F. (T.) nana comb. nov.

- Anterior lobes of carapace clearly more robust, the anteromedian ones rather triangular, the anterolateral ones conical. The two anteromedian lobes much longer than the anterolateral ones. Pedipalpal femur unusually attenuated, $2.06 \times$ (male) longer than broad. Pleural membrane with a dorsal row of 10 and a ventral row of 11 sclerotised pleural platelets. (South Africa)...... F. (T.) parva

9 Pronounced and triangular dorsomedial process on prolateral corner of palpal femur near its base is absent. All four anterior lobes of the carapace long and triangular, the anteromedian ones somewhat longer than the anterolaterals. Pedipalpal femur $1.66 \times$ (female) longer than broad. Pleural membrane with a dorsal and a ventral row of 15-15 sclero. tised pleural platelets. (South Africa)

F. (T.) capensis

- A pronounced and triangular dorsomedial process on the prolateral corner of palpal femur near its base is present. All four anterior lobes of the carapace robust and rather conical, the anteromedian ones somewhat longer than the antero. 
laterals. Palpal femur length/width ratio is $1.70-1.73 \times$ (female) and $1.76 \times$ (male). Pleural membrane with a dorsal row of 15 and a ventral row of 14 sclerotised pleural platelets. (Maldives) .................................. F. (T.) obscura sp. nov.

10 Anteromedian lobes are approximately two times wider than the anterolateral ones. Dorsal line of chela concave, ap. proximately at the middle of fixed finger a strong protuberance is present. Pedipalpal femur $1.77-1.86 \times($ female) and 1.80-1.89x (male) longer than broad. (Kenya).

- $\quad$ Anterolateral lobes are clearly wider than the anteromedian ones .......................................................... 11

11 Anterolateral lobes at least two times broader than anteromedian ones and are flattened at their apical part. Pedipalpal femur $1.80 \times$ (female) and $1.61 \times$ (male) longer than broad (Democratic Republic of Congo)....................F. (T.) leleupi

- Anterolateral lobes less than two times broader than anteromedian ones and are triangular or at least rounded at their apical part

12 All four anterior lobes of carapace are placed equidistant from each other. Chelae are approximately as long as the palpal femora. Pedipalpal femur 1.72-1.90x longer than broad. Trichobothrium sb is closer to st than to $b$ on movable chelal finger (Seychelles).

- Anteromedian lobes are closer to each other than to the anterolateral ones. Chelae are distinctly shorter than palpal femora. Palpal femur length/width ratio is $1.90 \times$ (female). Trichobothrium sb is situated equidistantly between st and $b$ on movable chelal finger (Bangladesh, India, Sri Lanka)

F. (T.) indica

\section{Acknowledgements}

The authors thank Dr László Dányi for facilitating access to the HNHM material, and Edit Horváth (HNHM) for assistance in locating the collection data, as well as the collector Mr Győző Horváth. We are grateful for Dr Mark S. Harvey for comparing our specimens against other undescribed species from his collections, and to Mag. Christoph Hörweg for sending critical literature. We are grateful to the reviewers, Dr Mark S. Harvey and Edwin Bedoya-Roqueme, for their valuable comments on the manuscript.

\section{References}

Batuwita S, Benjamin SP (2014) An annotated checklist and family key to the pseudoscorpion fauna (Arachnida: Pseudoscorpiones) of Sri Lanka. Zootaxa 3814: 37-67. https://doi.org/10.11646/zootaxa.3814.1.2

BeierM(1932)Pseudoscorpionidea I. Subord. Chthoniinea et Neobisiinea. Das Tierreich 57: 1-258. https://doi.org/10.1515/9783111435107

Beier M (1947) Zur Kenntnis der Pseudoskorpionidenfauna des südlichen Afrika, insbesondere der südwest- und südafrikanischen Trockengebiete. Eos, Madrid 23: 385-339.

Beier M (1955) Pseudoscorpionidea. In: Hanstrom B, Brinck P, Rudebeck G (Eds) South African Animal Life. Results of the Lund Expedition in 1950-1951, vol 1: 263-328. Almquist and Wiksell: Stockholm.

Beier M (1959) Pseudoskorpione aus dem Belgischen Congo gesammelt von Herrn N. Leleup. Annales du Musée du Congo Belge, Sciences Zoologiques 72: 5-69.

Beier M (1964) Weiteres zur Kenntnis der Pseudoskorpioniden-Fauna des südlichen Afrika. Annals of the Natal Museum 16: 30-90.

Beier M (1966) Ergänzungen zur Pseudoskorpioniden-Fauna des südlichen Afrika. Annals of the Natal Museum 18: 455-470.

Benavides LR, Cosgrove JG, Harvey MS, Giribet G (2019) Phylogenetic interrogation resolves the backbone of the Pseudoscorpiones tree of life. Molecular Phylogenetics and Evolution 139: 106509. https:// doi.org/10.1016/j.ympev.2019.05.023

Chamberlin JC (1931) The arachnid order Chelonethida. Stanford University Publications, Biological Sciences 7: 1-284.
Droxler AO (1992) General Cenozoic evolution of the Maldives carbonate system (equatorial Indian Ocean). Bulletin Des Centres de recherches Exploration-Production Eld Aquitaine 16: 113-136.

Gerlach J, Marusik, Y (2010) Arachnida and Myriapoda of the Seychelles islands. Siri Scientific Press. 435 pp.

Hirst S (1911) The Araneae, Opiliones and Pseudoscorpiones. Transactions of the Linnean Society of London, Zoology (2) 14: 379-395. https://doi.org/10.1111/j.1096-3642.1911.tb00535.x

Harms D, Dunlop JA (2017) The fossil history of pseudoscorpions (Arachnida: Pseudoscorpiones). Fossil Record 20: 215-238. https:// doi.org/10.5194/fr-20-215-2017

Harvey MS (1989) A new species of Feaella Ellingsen from north-western Australia (Pseudoscorpionida: Feaellidae). Bulletin of the British Arachnological Society 8: 41-44.

Harvey MS (1992) The phylogeny and classification of the Pseudoscorpionida (Chelicerata: Arachnida). Invertebrate Taxonomy 6: 13731435. https://doi.org/10.1071/IT9921373

Harvey MS (2013) Pseudoscorpions of the World, version 3.0. Western Australian Museum, Perth. http://museum.wa.gov.au/catalogues-beta/pseudoscorpions [Accessed: 01. July 2020]

Harvey MS (2018) Two new species of the pseudoscorpion genus Cybella (Pseudoscorpiones: Feaellidae) from Malasian caves. Zoologischer Anzeiger 273: 124-132. https://doi.org/10.1016/j. jcz.2017.12.008

Harvey MS, Abrams KM, Beavis AS, Hillyer MJ, Huey JA (2016a) Pseudoscorpions of the family Feaellidae (Pseudoscorpiones: Feaelloidea) from the Pilbara region of Western Australia show extreme short-range endemism. Invertebrate Systematics 30: 491-508. https://doi.org/10.1071/IS16013

Harvey MS, Andrade R, Pinto-da-Rocha R (2016b) The first New World species of the pseudoscorpion family Feaellidae (Pseudoscorpiones: Feaelloidea) from the Brazilian Atlantic Forest. Journal of Arachnology 44: 227-234. https://doi.org/10.1636/JoA-S-16-007

Harvey MS, Ratnaweera PB, Udagama PV, Wijesinghe MR (2012) A new species of the pseudoscorpion genus Megachernes (Pseudoscorpiones: Chernetidae) associated with a threatened Sri Lankan rainforest rodent, with a review of host associations of Megachernes. Journal of Natural History 46: 2519-2535. https://doi.org/10. $1080 / 00222933.2012 .707251$ 
Henderickx H, Boone M (2014) The first fossil Feaella Ellingsen, 1906, representing an unexpected pseudoscorpion family in Baltic amber (Pseudoscorpiones, Feaellidae). Entomo-info 25: 5-11.

Henderickx H, Boone M (2016) The basal pseudoscorpion family Feaellidae Ellingsen, 1906 walks the earth for 98.000.000 years: an new fossil genus has been found in Cretaceous Burmese amber (Pseudoscorpiones: Feaellidae). Entomo-info 27: 7-13

Henderson R, Johnson D (2016) The Geology of Australia. $3^{\text {rd }}$ edition. Cambridge University Press, 375 pp. https://doi.org/10.1017/ CBO9781139923866

Judson MLI (2007) A new and endangered pseudoscorpion of the genus Lagynochthonius (Arachnida, Chelonethi, Chthoniidae) from a cave in Vietnam, with notes on chelal morphology and the composition of the Tyrannochthoniini. Zootaxa 1627: 53-68. https://doi. org/10.11646/zootaxa.1627.1.4
Judson MLI (2017) A new subfamily of Feaellidae (Arachnida, Chelonethi, Feaelloidea) from Southeast Asia. Zootaxa 4258: 1-33. https:// doi.org/10.11646/zootaxa.4258.1.1

Kench PS, McLean RF, Nichol SL (2005) New model of reef-island evolution: Maldives, Indian Ocean. Geology 33: 145-148. https:// doi.org/10.1130/G21066.1

Mahnert V (1978) Contributions á l'étude de la faune terrestre des îles granitiques de l'archipel des Séchelles. Pseudoscorpiones. Revue de Zoologie Africaine 92: 867-888.

Mahnert V (1982) Die Pseudoskorpione (Arachnida) Kenyas II. Feaellidae; Cheiridiidae. Revue Suisse de Zoologie 89: 115-134. https:// doi.org/10.5962/bhl.part.82432

Tullgren A (1907) Chelonethiden aus Nathal und Zululand. In: Professor T. Tullberg (Ed.) Zoologiska Studier Tillagnäde 216-236. Almquist and Wiksells: Uppsala. 